\title{
ROLE-PLAY IS ONE OF THE METHODS OF TEACHING A FOREIGN LANGUAGE
}

\author{
Mamirova Gulnoza Ikrom qizi \\ Practical English Language Department \\ English Faculty, Jizzakh State Pedagogical Institute named by Abdulla Khadiri, \\ E-mail: mamirova1994@list.ru
}

\begin{abstract}
The pronounced need of modern society for high-quality language education is supported at the state level. One of the content lines of the language component of teaching at school is the speech line, which ensures the development and improvement of skills and abilities in all types of student speech activity. The article examines roleplaying games, due to their didactic nature, allows solving the problems of developing the creative abilities of students, the ability to independently design their knowledge and apply them to solve cognitive and practical problems, navigate the information space, analyze the information received, since at different moments of cognitive experimental or applied in creative activity, students use the totality of all the listed intellectual skills and abilities.

Key words: increasing the effectiveness of learning, an explosion of motivation, increasing interest, cognitive interests, vocabulary games, grammar games.

\section{Introduction}

Teachers from all over the world are looking for ways to improve the effectiveness of teaching a foreign language. In our country, the problem of the effectiveness of training is being actively developed based on the use of the latest achievements of psychology, computer science and the theory of cognitive management. As the analysis of pedagogical practice in modern secondary schools shows, in recent years the transition to humanistic methods of teaching and upbringing of children has clearly emerged. In recent years, domestic science has made significant progress in the introduction of new psychological and educational technologies. One of these innovative methods is play. Play evokes involuntary attention even where, under normal conditions, the teacher has to be content with voluntary attention, sometimes resorting to disciplinary measures.
\end{abstract}

\section{Main part}

A properly played game improves discipline. Interest, attention and conscious discipline are the key to the strength of knowledge. Play, especially with a pronounced element of play, causes the students to be extremely active. But the task of the teacher is to direct the activity of students in the right direction to achieve the set goal. Opportunities for enhancing the educational process are two use of role-playing games. It is known that role play is a conditional reproduction by participants of real practical activities of people, creates conditions for real communication. The effectiveness of teaching here is primarily due to the explosion of motivation, increased interest in the subject. Role-play motivates speech activity, as the trainees find themselves in a situation where the need to say something, ask, find out, prove, share something with the interlocutor actualizes. Unlike dialogue or play, which teaches how to say, role play answers the questions with nothing (motive) and why (purpose) need to say something.

Thus, the focus of the partners becomes the content of the conversation, which in itself is a positive factor. Learners are clearly convinced that language can be used as a means of communication. The game activates the desire of children to contact each other and the teacher, creates conditions for equality in speech partnership, destroys the traditional barrier between teacher and student. The game gives the opportunity for timid, insecure students to speak and thereby overcome the barrier of uncertainty. In a normal discussion, students - leaders, as a rule, seize the initiative, while timid ones prefer to remain silent.

In a role play, everyone is given a role and must be an active partner in verbal communication. In games, schoolchildren master such elements of communication as the ability to start a conversation, support it, interrupt the interlocutor, at the right time agree with his opinion or refute it, the ability to purposefully listen to the interlocutor, ask clarifying questions, etc. Role play teaches you to be sensitive to the social use of a foreign language. A good interlocutor is often not the one who uses the structures better, but the one who can most clearly recognize (interpret) the situation in which the partners are, know the information that is already known (from the situation, experience) and choose those linguistic means that will be most effective for communication. Almost all learning time in the roleplaying game is devoted to speech practice, while not only the speaker, but also the listener is as active as possible, since he must understand and remember the partner's remark, relate it to the situation, determine how relevant it is to the situation and the task of communication, and respond correctly to the replica. Games have a positive effect on the formation of the cognitive interests of schoolchildren, contribute to the conscious mastering of a foreign language. They contribute to the development of such qualities as independence, initiative, fostering a sense of collectivism. Students work actively, enthusiastically, help each other, listen attentively to their comrades, the teacher only manages educational activities. Let's name the basic requirements for role-playing games.

The game should stimulate the motivation for learning, arouse interest and desire in schoolchildren to perform the task well, it should be carried out: on the basis of a situation adequate to the real communication situation. The role-play must be well prepared in terms of both content and form, and clearly organized. It is important that students 
are convinced of the need to perform well in a particular role. Only under this condition will their speech be natural and convincing. The role play should be accepted by the whole group. It will certainly be held in a friendly, creative atmosphere, it evokes a feeling of satisfaction and joy in schoolchildren. The freer the student feels in the role-playing game, the more initiative he will be in communication.

Over time, he will have a sense of confidence and his strength, in the fact that he can perform different roles. The game is organized in such a way that students can use the language material they are practicing with maximum efficiency in active speech communication. The teacher himself certainly believes in role-playing, in its effectiveness. Only under this condition will he be able to achieve good results. The role of the teacher in the preparation and conduct of the game is constantly changing. At the initial stage of work, the teacher actively controls the activities of the students, but gradually he becomes only an observer. This coincides with the provisions of didactics on the role of the teacher in the educational process. In modern Soviet didactics, much attention is paid to the organization of active independent activity of schoolchildren in the assimilation of new knowledge, the formation of skills and abilities. In this regard, the teacher's ability to establish contact with children is of great importance.

Creation of a favorable, benevolent atmosphere in the classroom is a very important factor, the importance of which cannot be overestimated. In the course of the game, the teacher can sometimes take on some role, but not the main one, so that the game does not turn into a traditional form of work under his leadership. It is desirable that the social status of this role helps him to unobtrusively direct verbal communication in the group. Usually, the teacher takes on roles only at the beginning, when the students have not yet mastered this type of work. In the future, this is no longer necessary. During the game, strong learners help the weak. The teacher, on the other hand, controls the process of communication: he approaches one or another student who needs help, then makes the necessary adjustments to the work. During the game, the teacher does not correct mistakes, but only imperceptibly for the students writes them down in order to discuss the most typical ones in the next lesson.

Role-play can be used both at the initial stage of training and at the advanced stage. It always presents a situation that is created both by verbal and non-verbal means: pictorial, graphic, monologue / dialogical text, etc. The situation indicates the conditions for the action, describes / actions to be performed and the task to be solved. The action and task can be simple or difficult to complete; therefore, communication between partners will be either simple or complex both in content and in the use of linguistic forms. In a situation, it is necessary to provide information about the social relationships of partners, for example, official / unofficial. The roles section contains a list of roles. The description of the role is given in the role card, while the information can be presented in detail: information is given about the person (kind, honest, lazy, etc.), about his life and speech experience, about habits, hobbies, etc. However, the information should not be presented in too much detail, because in this case the participant of the game will be deprived of the opportunity to show creativity. The description can be brief so that the student can conjecture the image of the character, the role of which he will play. Students need to be given time to get into the role. Each student of the role-playing game performs speech actions due to the communication situation, but for each of them there is a certain freedom of action, speech actions. Roles are assigned by the teacher, and the students themselves can choose them. It depends on the characteristics of the group and the personal characteristics of the students, as well as on the degree of their proficiency in foreign languages.

When discussing the game, evaluating the participation of schoolchildren in it, the teacher should show tact, especially when assessing the results of the first role-playing game. A negative assessment of the activities of its participants will inevitably lead to a decrease in activity. It is advisable to start the discussion of the results of the game with good moments and only then move on to the disadvantages. If there is such an opportunity, you need to record the course of the game on magnetic tape, and then, together with the students, listen to the phonogram of either the entire game or its individual fragments. When analyzing the game, you can record the necessary information from the tape recorder onto the board.

The photographic materials of the game give the teacher a clear idea of what did not work out in the game, which language forms were used inappropriately to the situation, which fell out of sight during the preparation of the game. All this gives the teacher the opportunity to take into account the disadvantages when conducting subsequent role-playing games. The school reform poses serious tasks for teachers to intensify the educational process and improve teaching methods. Secondary schoolchildren have a great desire to learn a foreign language, however, due to illness, as well as for a number of reasons that lead to the fact that children miss classes, this subject loses its attractiveness for them, lagging students consider it one of the most difficult, and, therefore, unloved. The main task of the teacher is to ensure that children do not lose interest in the subject, so that the material offered to the student is accessible by difficulty. Games are of great help in solving these issues. Their use gives good results, increases the interest of children in the lesson, and allows them to concentrate their attention on the main thing - mastering speech skills in the process of a natural communication situation during the game. They use games in learning a foreign language in all grades, but the nature of the material and tasks change from class to class. In our opinion, role-playing games should be classified as follows: lexical, grammatical, memory-developing games, dramatic games for creative interpretation. Lexical games have goals:

- to train students in the use of vocabulary in situations close to the natural setting;

- to intensify the speech-thinking activity of students; -to develop the speech reaction of students;

- to acquaint students with the compatibility of words. Grammar games have the following goals:

- to teach students the use of speech patterns containing certain grammatical difficulties; 
- create a natural situation for the use of this speech pattern; material

- to develop speech activity and independence of students. Games include the most important grammatical

- verbs, tense verb forms: indirect speech, subjunctive mood. Most games are based on a scoring competition.

Properly organized games evoke and support students' interest in learning a foreign language. Anticipating the joy of the game, the guys are happy to study foreign language lessons. When an interesting game is held, students have a desire to study, memorize a foreign language, practically master it. These are some of the keys to dealing with student passivity. For everyone, especially those lagging behind, play is an incentive to master the language. However, you shouldn't get too carried away with games. Not all games are equally interesting.

\section{Conclusion}

Games with a pronounced "game element" generate more interest than other games. It is necessary to gradually introduce more and more new types of games. In one lesson, for example, a game is played for the winning row, in the other - for "forfeits", then for guessing, etc. If in one case the row that wrote the words correctly and quickly won, then in the other - the row is the best who described the picture, in the third- who made a dialogue better than others did, etc. Today they made up a word, and after a few lessons or weeks the student must guess which subject the class was thinking. The gradual introduction of new elements into the educational process sets in motion the basis of students' involuntary attention - interest - and contributes to the maintenance of interest in learning a foreign language. If students show excessive interest in the very course of the game, the latter threatens to turn into an end in itself, a game - entertainment. To prevent this from happening, it is necessary to thoroughly think over the organization of the game in advance so that the interest and attention caused by the course and form of the game are directed to the practical mastery of the language, therefore, the game should be pedagogically purposeful, it should not be an end in itself, but a means of teaching a foreign language. Game evokes involuntary attention even where, under normal conditions, the teacher has to be content with voluntary attention, sometimes resorting to disciplinary measures. A properly played game improves discipline. Interest, attention and conscious discipline are the key to the strength of knowledge.

\section{References}

1. Bakirova H.B. Teaching foreign language terminology at non-language universities. International journal of discourse on innovation. Integration and education. Volume: 01 Issue: 01.2020 http://summusjournals.uz/index.php/ijdiie

2. Bakirova H.B. Formation of terminological competence in ESP education. Novateur publications. Journal NX- A Multidisciplinary Peer Reviewed Journal, ISSN No: 2581 - 4230 VOLUME 6, ISSUE 11, India.-2020. P 63. 